\title{
MIGRATORY CONTROL POLICIES IN SPAIN AND THE UNITED STATES
}

\author{
Paulo Miguel MadeirA ${ }^{1}$
}

In recent decades migration has become one of the most striking aspects of modern-day societies due to the extension and generalization of migrant flows between states, mostly driven by major income differences between countries of origin and destination, as well as humanitarian catastrophes (natural or war disasters). As such, it has become the source of social and political tensions especially in host countries. In this context, the study of the outcomes of immigration policy, normally presented by politicians as a means to control migration flows into destination countries, is particularly relevant to evaluate the results achieved against initial objectives.

The objective of this book, edited by Izquierdo and Cornelius ${ }^{2}$, is "to determine if the different measures regarding immigration controls applied in the United States (to discourage illegal immigration through the Mexican border) and in Spain over the last ten years (to regulate access, legal status and employment of migrant workers) changed the migratory behaviour in the direction intended by the legislator" (p. 9), bearing in mind that both countries are at the forefront of efforts to control south-north international migration. Extensive fieldwork was conducted in Spain and the United States, as well as in Mexico, Ecuador and Morocco, employing both quantitative and qualitative methods.

The book begins with two chapters authored by Wayne A. Cornelius and Antonio Izquierdo, respectively, on US control policies of Mexican immigrants and on the policy of mass regularizations in Spain. Six other chapters follow on exploring more specific features of the characteristics of immigration and related policy in both countries, five of which are dedicated to the Spanish experience, and just one to the United States - "As immigration control policies in the United States have determined migration from Mexico".

The empirical results presented in this last chapter, obtained from a survey conducted, both in the US and Mexico, of migrants from the Mexican municipality of Tunkás, on the Yucatán Peninsula, led the authors to conclude that "immigration control (both on the border and internal) has just a discouraging effect on these Mexicans decisions to emigrate" (p. 300), but has a small impact on flows. In 2008, the National Security Agency explained the decre-

1 Researcher at the Centre for Geographical Studies, University of Lisbon. E-mail: paulo. madeira@campus.ul.pt

2 Cornelius W A, Izquierdo A (eds.) (2012) Politicas de control migratório - Estudio comparado de España y EE.UU., Edicions Bellaterra, Barcelona. 
ase in the number of arrests of illegal migrants at the Mexican border as the result of increased surveillance - which is the core of US migration control strategies - but this study also points out the limited effect of this policy. Alternatively, the authors propose four hypotheses thought to have greater explanatory power.

First, a greater control of the border reduces the circulation of Mexican emigrant flows, given the increased physical and economical risks of crossing it. It reduces the number of crossings, therefore decreasing the number of migrants who can be arrested. At the same time, new entries and creative methods appear (partly replacing the traditional ones), which the Border Patrol has not yet been able to neutralize. On the other hand, and in recent years, there is a growing dependence on "professionals" to help with border crossing, the so called "coyotes", as they grant a better chance of a successful crossing, even if not on the first attempt. Finally, in the context of the current economic climate, a decline in the demand for immigrant labour in the US led to a reduction in the number of potential immigrants.

Furthermore, a series of internal initiatives to control illegal immigrants in the US were implemented, including incursions by US Immigration and Customs Enforcement agents in places of work, increased random traffic control and the introduction of restrictions in access to healthcare, education and driving licenses, along with federal measures to detect forged documents. In this case, the life of the Tunkasenhos living in the US became "more difficult" (p. 299), but that does not mean that they want to go back to Mexico, due mainly to wages differences ("though they live in a permanent state of fear of being arrested and expelled from the country"), nor it had particularly affected their decisions to emigrate or stay in Mexico.

While Mollie Cohen, Jonathan Hicken and Jorge Narvaez did not find significant results in terms of a reduction in migration, they uncovered some unintended consequences, such as the detention of undocumented immigrants in the US (decrease of circular migration), increased incentives for people-trafficking and the death of thousands of immigrants trying to enter the US illegally (p. 254). On the other hand, the new methods of internal control, such as deportation, may have worked to deter people from reporting crimes to the police.

The results of the aforementioned study led Wayne A. Cornelius to conclude in the first chapter of the book ("Evaluating US Immigration Control Policy: What Mexican Migrants Can Tell Us") that the starting point for a reform of the immigration system in the US should be the recognition that the economic conditions in both countries are "what basically determine if a possible immigrant is willing to invest thousands of dollars and risk his life in the desert to enter the United States, and not the obstacle course that is being built on the border" (p. 42).

Moreover, the author reminds us that the economic cycles are a more efficient instrument for immigration control to the United States, as evidenced by the Great Depression (1930s) period, the only time over the past 100 years during which Mexican immigration to the country stopped. Moreover, the survey conducted in Mexico in early 2009 shows that the economic crisis of 2007-2009 in the US reduced illegal immigration much more than any other government measure over the last years.

Therefore, it can be concluded that, to be effective, US migration control policy should change the cost/ benefit perceptions of potential immigrants from Mexico, as well as from other labour-exporting countries (p. 22). However, such a task will be difficult as long as the real wage difference between these two countries is maintained as regards low-skilled workers, which at the time of this research was at least eight to one. 
The book endorses the concept that the inadequacy of migration control policy in the US results from the limited intervention capacity of the United States over migration flows, along with a lack of understanding of the nature of the migration phenomenon among policy makers. It leaves no room - or very little room - for the hypothesis that politicians are simultaneously trying to satisfy two contradictory interests: the interest of the social sectors averse to immigrants and the interest of employers seeking for a cheap and obedient workforce. It may well be the case that, trying to apparently meet their electorate demands, they are indeed helping some business sectors. However, Cornelius does not always take the power discourse at face value. In his own words, "many elected representatives believe, or wish that their voters believe, that the government of the United States has, in fact, the capacity to manage international migration flows in order to reach the estimated results and see minimized unintended consequences". According to the author, this ability is limited, as well as that of the other big countries importing cheap workforce.

In the case of Spain, the migration phenomenon is more recent, and can be correlated with the increase in GDP and foreign investment. At that time, Spain saw itself as a country of emigration and transit to the richer countries of Europe.

In the second chapter of this book, which focuses on the Spanish case, Antonio Izquierdo writes about "the repercussion of the massive regularizations of emigrants in the two aspects of migration control" - that of inflows and that of immigrants already present in the country (p. 45). He wants to evaluate the "call effect" that the regularizations had on migration flows, and the benefits of the "inclusion effect" resulting from those processes. His aim is to investigate if "the call effect on the flows is smaller than the inclusion effect on the society that receives them", based on the cases of Moroccan and Ecuadorian immigrants. Or, in other words, to what extent the regularization leads to an increase in the flows and unbalances the policy of immigration control.

In eight years, Spain has gone through eight processes of regularization, which, on the whole, comprehended 1.5 million people. The largest of all took place in 2005, and was known as an "operation of normalization", serving to regularize more than half a million people and marking "the end of the Tolerated Irregularity Model". The economic crisis of 2008 then stressed "the end of a migration cycle in Spain", with the double consequence of more regularity and less entries (p. 97). During this process, the country became the main place of entry to the European Union for immigrants coming from Africa and, most likely, also from Latin America, as Cornelius and Izquierdo explain in the introductory chapter.

The transformation of Spain into an important migration destination began at the beginning of the 1990's, with migration into the country swelling at the turn of the century, as seen from the data presented in chapter 2 . Thus, at the beginning of the 21 st century there were 895 thousand foreigners with no residence permit, but by the end of 2010 there were about five million. The regularization of immigrants is considered to be the result of the Tolerated System of Irregularity, which, according to Izquierdo, prevailed in the first years of the intensification of immigration flows, to reduce labour costs in some sectors.

The Tolerated System of Irregularity is, in turn, considered a result of the original idea - which turned out to be wrong - that Spain was just a country of passage for immigrants on route to other destinations in the EU, meaning that the authorities did not worry about the number of foreigners entering the country (p.51). The government considered the best model to incorporate migrants in the labour market was as a temporary labour force in low-skilled tasks. However, over time the irregular system ended up producing employees in the services who, in the meantime, had been joined by their families (p. 49). 
In this system, during the 1990's, the cultural context resulted in compassion and empathy towards the immigrants - after all, Spain had been, just like Portugal, a country of emigration. According to Izquierdo, immigrants were seen as temporary and their regularization was supported by the population in general. The irregularity of migrants' legal status was also based on a generalized culture of labour irregularity and on an over-zealous bureaucracy regarding regulation and management of foreigners. This irregular hiring helped to maintain an intensive labour model, largely based in the black economy. The bureaucratic management of this pattern resulted in a lot of institutional irregularity, mainly due to the slowness in the renewal of authorizations and its geographical and sectorial rigidity (p. 54).

In 2000, both public fears on immigration and the political discourse on immigration of the newly elected right-wing Popular Party (PP) gave way to a "moment of zero tolerance" which replaced the "irregularity consented by businessmen, the government and a portion of the civil society" (p. 55). The PP planned to erect a "Model of Orderly Immigration" beginning with a restrictive legislative reform and a new legalization programme, which was presented as being the last wide-scale regularisation, given that its effect was understood to be negative.

Nevertheless, on average, half a million immigrants entered every year until 2008, after which point an abrupt fall took place, coinciding with the financial and economic crisis in the West and the stratospheric levels of unemployment in Spain. In the meantime, the regularisation of 2005 marked the end of the "Tolerated Model of Irregularity" and by 2006 the European Union set up four special funds destined for immigration control, of which Spain became prime beneficiary.

The country has been trying to waterproof its southern frontiers, with little success until around the time of this study, as is explained in the introduction. With that objective, the Spanish Government cooperated with countries outside the EU in an effort to control the flow of immigration, by convincing external governments to filter individuals who want to enter the Community territory. Bilateral agreements were made with Latin-American and Maghreb countries - where Morocco played a significant role.

Nevertheless, in Chapter 4 ("The recent evolution of migration control policies in Spain"), Antía Pérez Camarés contends that migratory control policies "led to the reduction of the number of immigrants detained while trying to illegally enter Spain, which implies a dissuasion of intentions right from the start. If this tendency continues in the coming years, it may led to a containment of irregular migration flows, which would point to the relative success of the Community program Frontex, of the collaboration of Morocco in containing sub-Saharan immigration and of the cooperation with the emitting countries" (p. 205). However, this is not fully in accordance with the idea presented in the introduction regarding the lack of success in this domain, even if the "irregular immigration to Spain has not stopped" (ibid.). The authors contend that, despite the tightened border vigilance, "little attention was given to the powerful factor of attraction that the informal economy represents, and the cooperation efforts for development were not enough to alleviate the factors which gave cause to migration from the countries of origin".

To the book's editors, the main external limitation to Spanish immigration control policies is the lack of a unified migration policy in the EU, and the unequal distribution of resources to control immigration across the southern European border. On the other hand, they consider that the electoral confrontation between the PP and the PSOE on this matter reinforces this problem, due to the several exceptional regularizations that gave legal documents to hundreds and thousands of immigrants in Spain. PP sees the regularizations as attracting 
more immigrants and it discredited such regularizations and has put PSOE on the defensive.

But the special program of regularizations "did not work as a powerful magnet" for the respondents in this study, as "only $15.7 \%$ stated that the recent regularization program had been an influent factor (not necessarily the dominant one) in their decision to immigrate" (p. 21). The empirical evidence clearly relates migration flows with transnational immigrant networks and integration processes. Even so, these regularization processes are considered "a dream that generates monsters", once "the amnesties attract new undocumented people, and so the benefit of the process gets lost" - as some immigrants anticipate an already planned entry into Spain, and others change their migration plans to benefit from the legalization programme (p. 59).

In Chapter 2, the "call effect" of regularizations is evaluated, although the answers are not very conclusive. Thus, it fails to answer the research objective. The benefits of the "inclusion effect" resulting from the process of regularization are less easy to follow, as they are dispersed throughout the 55 pages of the paper. As such, this chapter would benefit from more concise conclusions. We learn that "the majority of Moroccan and Ecuadorian immigrants resided legally in Spain due to the massive regularizations and it is admissible to extend this conclusion to all the immigrants from outside the Community" (p. 93); and that, "after normalization and its consequences in the settling of the immigrated population, the center of gravity of the integration process moves from the central government to the autonomous and local governments" (p.98).

In their study of Moroccan and Ecuadorian immigrants, the authors do not meet their initial objective of evaluating if the "call effect on the flows is smaller than the inclusion effect on the foster society". However, perhaps from the information in the text an experienced migration researcher may be able to reach a conclusion. Nevertheless, conclusions are drawn about the impact of other aspects of migration policies in Spain. For instance: "imposing visas leads to an increase of the discontinuous irregularity, while permanent secrecy becomes obvious when Government increases border control unilaterally" (p. 91).

As referred to previously, "the normalization marks the end of the Tolerated Model of Irregularity and the economic crisis of 2008 stresses the end of a migration cycle in Spain", indeed, because for the first time in many years the migration balance was negative in 2011 . This allows us to draw a parallel with the USA, where the economic cycles have been the most efficient way to regulate immigration flows - however, this is not made explicit in the text.

This brings us to another issue regarding the comparative nature of the book. While the book was presented as a "comparative study of Spain and the USA", little was done to compare the two cases. The cases are presented in different moments, and no mutual reference was made by the authors of the different chapters. Still, this is understandable, since we are dealing with specific aspects of each country. A global reading, which could have been achieved in the conclusion, comparing the policies of both countries - their successes and failures - is missing. As a matter of fact, the only conclusive statements can be found in the introduction, where we can see the following mutual reference to both countries: the policymakers of both countries, as well as of other countries that import their labour force, "usually ascribe great efficiency to the migration control measures they applied (or intended to apply)", despite "a large number of failures when it comes to the control of 'undesired' immigration from Third World countries".

The remarks about the organization of the text and the lack of a comparative perspective reveal some gaps in the editing work, which extend to more prosaic aspects. However, that 
is not to say that the same applies to the research work. All the chapters present meticulous empirical work, with detailed analysis and enriching conclusions that could be extremely useful for those studying migration phenomena and for politicians concerned with making informed policy decisions.

Besides the aforementioned chapters, we can also find papers on "The migration process of Moroccan and Ecuadorian foreigners in Spain" (by Belén Fernández Suárez), "Integration and migration establishment policies" (Rosa Maria Soriano Miras and Juan Ignacio Rico Becerra), "Participation in the labour market of Ecuadorians and Moroccans in Spain" (Concha Carrasco and Dirk Godenau) and "Networks, markets and policies. Combination of factors in the migration process from Ecuador to Spain" (Miguel Laparra Navarro). 